\title{
Comparing demand functions when different price manipulations are used: Does unit price help?
}

\author{
CATHERINE E. SUMPTER, WILLIAM TEMPLE, and T. MARY FOSTER \\ University of Waikato, Hamilton, New Zealand
}

\begin{abstract}
Six hens pecked a key (Experiment 1) or pushed a door (Experiment 2) to obtain food reinforcement. In both experiments and as an analogue of price changes, the response requirements were varied in two ways: by increasing the number of responses required and by increasing the required force of each response. The two price manipulations (response number and response force) had different effects on behavior and produced different-shaped demand functions when the rates of consumption were plotted logarithmically against the price analogues. Irrespective of response topography, when the number of required responses was varied, the data paths appeared linear, with slopes close to -1.0 . When the required force of each keypeck and doorpush was varied, the data paths were clearly curved, with increasingly steep downward slopes as the force increased. Using the concept of unit price did not fully remove the different effects of the two price manipulations. Those differences are best attributed to the differing times needed in order to complete each response unit under those price manipulations.
\end{abstract}

Dawkins $(1983,1990)$ proposed that behavioral economics is an ideal framework for determining the types of commodities or environmental events that are important to an organism and that therefore may be necessary to its welfare. One economic concept useful in the assessment of animal needs is the demand function. In animal experiments, demand functions are generated by increasing the price of a commodity, usually the number of responses required in order to obtain that commodity, and then plotting total consumption or consumption rate against price (on logarithmic scales). If consumption of a commodity decreases less than the rate of price increase, it is assumed that the animal has a high degree of need for that commodity (Dawkins, 1990; Hursh, 1980, 1984). This pattern is referred to as inelastic demand and is reflected in a demand function with a slope less negative than -1.0 . Demand functions with slopes equal to -1.0 show unit elasticity, and reflect the fact that consumption decreases at the same rate as the rate of price increase. If consumption decreases faster than the rate of price increase, demand is said to be elastic. An elastic demand function has a slope more negative than -1.0 , and implies that the commodity being worked for may not be a need in welfare terms (Dawkins, 1990). In many animal experiments, the demand functions found are curvilinear, reflecting inelastic demand across low to moderate prices and elastic demand across higher prices.

We thank Jenny Chandler and the students at the Animal Behaviour and Welfare Research Centre, Hamilton, New Zealand, for their help in running this experiment. Reprints and the raw data for all parts of the experiment can be obtained from the first author. Address correspondence to the first author at the Psychology Department, University of Waikato, Private Bag 3105, Hamilton, New Zealand (e-mail: csu@waikato.ac.nz).
Although in most animal experiments concerned with assessing demand, price is increased by increasing the number of responses required per reinforcer (commonly using a fixed-ratio [FR] schedule), some researchers (e.g., Alling \& Poling, 1995; Sumpter, Temple, \& Foster, 1999) have suggested that increasing the force required in order to make each response may also be an appropriate means of manipulating price. To date, only one study (Sumpter et al., 1999) has compared the effects of these different price manipulations on demand functions.

Sumpter et al. (1999) compared demand functions produced by hens keypecking and doorpushing under increasing FR schedules, and doorpushing under increasing force requirements. In all conditions, the hens were responding for 3 -sec access to wheat, the experimental sessions were short, and consumption was expressed as reinforcers obtained per minute (i.e., consumption rate). Irrespective of whether keypecking or doorpushing was required, and irrespective of the force required in order to push the door, the demand functions generated by the session-to-session increases in FR requirement were relatively linear and downward sloping, indicating elastic demand. In contrast, when price was manipulated by increasing the force required to push the door at several FR requirements, all of the resulting demand functions were curvilinear. Demand was relatively inelastic across low to moderate force requirements and highly elastic across higher force requirements. On the basis of their results, Sumpter et al. (1999) cautioned against placing high reliance on any single determination of demand, especially when considering questions regarding animals' needs and, hence, their welfare.

Sumpter et al. (1999) suggested that the differences in the shapes of the functions could be accounted for in terms 
of the different ways in which the two price manipulations affect the minimum time needed to complete each response requirement. Ratio increases necessarily increase this time, whereas increases in required response force may not. Since Sumpter et al.'s (1999) animals responded at a fairly high and constant rate (i.e., close to the maximum rate possible) in all experimental sessions, doubling the FR size effectively doubled the time taken to complete the response requirement and, therefore, approximately halved consumption rates. As a consequence, approximately linear demand functions with slopes close to -1.0 resulted, indicating unit elasticity. By contrast, increasing the force required in order to make a response (within a range) did not alter the time taken to make each response (or not to the same extent), so relatively constant consumption rates were observed across that range. When the force requirements became large, however, the consumption rates dropped abruptly. Thus, curvilinear demand functions showing inelastic demand functions across low to moderate forces and elastic demand across the higher force requirements resulted.

In an attempt to reconcile the differences in the shapes of the functions, Sumpter et al. (1999) reanalyzed their data in terms of unit price, a concept proposed by Hursh, Raslear, Shurtleff, Bauman, and Simmons (1988). Unit price is a cost:benefit ratio that specifies the effort required per unit of the reinforcer:

$$
\text { Unit Price }=\frac{\text { responses } \times \text { effort }}{\text { reinforcers } \times \text { value }} \text {. }
$$

In this model, responses refers to the number of responses required (i.e., FR schedule), effort is a general term that refers to all properties of the response requirement (e.g., duration and required force), reinforcers refers to the number of reinforcers received, and value encompasses all properties of the reinforcer (e.g., duration, size, concentration, potency, and caloric gain). An implicit assumption within this model is that an increase in FR requirement (such as doubling the FR size) is functionally equivalent to the same increase (i.e., doubling) in required response force. It is also implied that consumption will be constant at a given unit price, irrespective of the FR and response-force requirements making up that unit price. For example, the consumption obtained when a single $200 \mathrm{~N}$ response is required should be the same as that obtained when 20 responses at $10 \mathrm{~N}$ or 100 responses at $2 \mathrm{~N}$ are required. This being the case, direct comparisons of demand curves for different commodities generated through the use of different price manipulations should be possible. Having accounted for the differences in response or cost parameters, any residual differences in elasticity of the demand functions may be attributable to properties of the commodities (i.e., reinforcers) alone.

Sumpter et al. (1999) reanalyzed their doorpush data according to the unit price model:

Unit Price $=$ FR schedule $\times$ force requirement.

When they did this, the functions moved closer together and became similar in shape, all showing a small degree of curvilinearity. There was more variability in the data around the lines fitted to the unit price functions than to the original functions (where the log consumption rates were plotted against $\log$ FR size or log force requirement), and the different shapes of the original functions were still detectable. That is, the force-derived functions were still clearly curved, and the FR-derived functions were virtually straight lines. They argued that since unit price is merely a multiplicative manipulation of the $x$-axis, and since the two price manipulations affected the time to complete each response requirement (and hence consumption rate) differently (i.e., producing different-shaped functions), complete unification to a single function may not be possible.

One common experimental practice when one is studying unit price changes or demand is to arrange conditions so that the subject obtains its total daily consumption of the commodity in the experimental session. These are termed closed economic conditions (Hursh, 1980). To maintain such conditions, researchers typically use fairly long, fixed-length, sessions and they measure the total amount or total number of units of the commodity consumed (e.g., Foltin, 1991; Hursh \& Winger, 1995; Raslear, Bauman, Hursh, Shurtleff, \& Simmons, 1988; Tsunematsu, 2001). In a number of studies (e.g., Foster, Blackman, \& Temple, 1997; Foster, Temple, Cameron, \& Poling, 1997), however, including that of Sumpter et al. (1999), consumption rate was the measure of demand used. When sessions are of fixed length, total consumption and consumption rate are essentially equivalent measures. The same-shaped demand functions will result from both measures, but they will be displaced up or down the $y$-axis by a constant multiplier. In open economic experimental conditions, where alternative sources of the reinforcer (usually food) are available outside the experimental session, the sessions are often terminated after a fixed number of reinforcer deliveries in order to limit total daily consumption. In such cases, the session lengths vary and total consumption and consumption rate will not be equivalent measures. Total consumption will necessarily be constrained to be identical at various prices. Consumption rate, by contrast, can differ from session to session, because it is free to vary. Thus, although economic theories such as unit price are typically couched in terms of total consumption, whenever the time available for responding differs from session to session then consumption rate will be the better measure for comparing demand.

As previously mentioned, studies of behavior under FR schedules in open economic conditions often maintain the open economic status of the sessions by limiting the number of reinforcers available in each session, and thus permitting postexperimental feeding. This was the case in the study reported by Sumpter et al. (1999) on unit price. In that study, sessions were terminated after 30 reinforcers or $40 \mathrm{~min}$ (whichever occurred first), so session length varied over the smaller FR and force requirements, and consumption rate was the measure of demand used. 
Although Sumpter et al. (1999) had a very large data set, it had not been generated with a unit price analysis in mind. Only a limited range of unit prices were examined, only a few of those unit prices were made up of more than one FR-force combination, and only the doorpush data were amenable to that analysis. Thus, any conclusions on the usefulness of a unit-price analysis based on Sumpter et al.'s (1999) data were tentative at best. The following experiments allowed for a more rigorous test of the utility of the unit price model by comparing consumption rate across a wide range of unit prices that were represented by more than one FR-force combination, using both keypeck and doorpush responses. For comparison with Sumpter et al.'s (1999) data set, the same open economic conditions and price manipulations were employed here and consumption rate was used as the measure of demand.

\section{EXPERIMENT 1}

In this experiment, we examined changes in hens' consumption rates across a range of unit prices using a keypeck response. For all five of the unit prices used, from three to five different combinations of FR and keyforce requirements were arranged to make up that unit price. In the first part of the experiment, the unit prices were generated by keeping the force required for pecking the key constant at each of several levels, and by increasing the FR requirement each session. In the second part of the experiment, the same unit prices were arrived at by keeping the FR requirement constant at several values and changing the minimum key-force requirement across sessions.

\section{Method}

Subjects. Five Brown Shaver hens, numbered 91-95, served as subjects. All hens were raised in a free-range environment and were approximately 4.5 years old when the experiment began. Hens 91 , 92, and 93 had had experience on a delayed matching-to-sample task, Hen 94 had participated in a study on the resurgence of behavior during extinction, and Hen 95 had been trained on a visual discrimination task. Immediately prior to this experiment, all of the hens had been responding on a weighted key. The hens were housed in individual ( $30 \mathrm{~cm}$ wide, $45 \mathrm{~cm}$ deep, and $43 \mathrm{~cm}$ high) cages where water was freely available. They were maintained at $80 \%$ $( \pm 5 \%)$ of their free-feeding body weights through daily weighing and, if necessary, supplementary feed (commercial laying pellets). Extra food was supplied when the hens' weights had fallen below their $80 \%$ weight, when they had received no reinforcers for two consecutive sessions, or when they were between series of experimental conditions. Grit and vitamins were supplied weekly.

Apparatus. A particle-board experimental chamber (measuring $42 \mathrm{~cm}$ wide, $57 \mathrm{~cm}$ deep, and $54 \mathrm{~cm}$ high internally) was used. A thick metal grid enclosed in a steel tray $(3.5 \mathrm{~cm}$ high) covered the floor. A hole $(7 \mathrm{~cm}$ wide and $10 \mathrm{~cm}$ deep), centered on the front wall $8.5 \mathrm{~cm}$ above the grid floor, allowed access to the food magazine. When raised, the magazine provided access to wheat and was illuminated by a $1-\mathrm{W}$ white bulb. A plastic response key $(3 \mathrm{~cm}$ in diameter) was also centered on the front wall, $36 \mathrm{~cm}$ above the grid floor. Two metal rods, both $1 \mathrm{~cm}$ thick, were attached to the top rear of the key. One of these rods was $3 \mathrm{~cm}$ long; the other was $6 \mathrm{~cm}$ long and had a pin attached $0.4 \mathrm{~cm}$ from the end, from which various weights could be hung. When operative, the key was illuminated from behind by a $1-\mathrm{W}$ red bulb and a minimum force of $0.5 \mathrm{~N}$ was required to activate it when unweighted. An electronic beeper provided an audible beep following each effective keypeck.

The force required to activate the key was increased by hanging weights from the pin attached to the long bar. Each weight yielded one of the force requirements to be examined in the experiment. These forces were $0.5 \mathrm{~N}, 1 \mathrm{~N}, 2 \mathrm{~N}, 3 \mathrm{~N}$, and $4 \mathrm{~N}$, measured with a calibrated spring balance (attached to the rear of the key through a small hole in the center).

All experimental events were programmed and recorded on a Compaq Prolinea 4/66 computer interfaced with a programmable control board and operating MED 2 software. Data were also recorded in a $\log$ book.

Procedure. The hens' consumption rates at unit prices of 10, 20, 40,60 , and 80 were examined. Each of those unit prices was made up of a range of different combinations of $F R$ requirements and required key forces. Throughout the experiment, each effective keypeck was signaled to the subject by a short $(30-\mathrm{msec})$ audible beep, and the completion of each FR requirement resulted in both the short beep and access to wheat for $3 \mathrm{sec}$. All sessions ended after 30 reinforcers or $40 \mathrm{~min}$ (whichever occurred first), and at least six sessions were conducted each week (Monday through Saturday).

During Conditions $1-3$, the force required to peck the key was held constant and the FR requirement was changed each session. Each condition consisted of two identical series of FR-requirement changes. In Condition 1, the key was unweighted so that a minimum force of $0.5 \mathrm{~N}$ was required to make an effective keypeck and the following FR values were used: 20, 40, 80, 120, 160. During Condition 2, a minimum force of $1 \mathrm{~N}$ was required for an effective keypeck and the FR values were changed according to the following sequence: 10, 20, 40, 60, 80. In Condition 3, required key force was held constant at $2 \mathrm{~N}$ and the series of FR values was $5,10,20$, 30,40 .

During Conditions 4-6, the FR requirement was held constant and the required key force was changed each session. Each condition consisted of two identical series of key force changes at a particular FR requirement. The FR requirements used during Conditions 4, 5, and 6 were FR 20, FR 10, and FR 5, respectively. The series of required key forces (in newtons) was $0.5,1,2,3$, and 4 during Condition $4 ; 1,2$, and 4 during Condition 5; and 2 and 4 during Condition 6. Table 1 shows the order of experimental conditions, together with the various FR and key force requirements and the corresponding unit prices.

\section{Results}

The logarithmic (to the base 10) consumption rates (based on session time excluding reinforcement time) from the two series of FR and force changes within a condition were analyzed separately and compared. There were no consistent differences in the log consumption rates obtained under each particular price in the two series across hens and conditions. Those obtained during Series 1 were not consistently faster or slower than those obtained during Series 2. Across the 11 possible comparisons for each hen, the standard deviations of the absolute differences in the log consumption rates were generally small, ranging from 0.027 to 0.3140 ( $\log _{10}$ units). For this reason, and to simplify the data presentation, only those from the second series of each condition were used in the analyses. Furthermore, certain combinations of FR and force occurred more than once. For example, the combination FR 20 and $0.5 \mathrm{~N}$, a unit price of 10, occurred during Condition 1 (in which force was held constant and FR was increased each session) and in Condition 4 (in which FR was held constant and the force was 
Table 1

Order of Experimental Conditions, Unit Prices Examined, and FR and Key-Force Requirements Used to Make up Those Unit Prices

Part 1: Key Force Constant, FR Increased Each Session

Condition No
Key Force $(\mathrm{N})$
$\frac{\text { Unit Price }}{10}$
20
40
60
80
1 0.5 2

\begin{tabular}{rrr}
\hline 20 & 10 & 5 \\
40 & 20 & 10 \\
80 & 40 & 20 \\
120 & 60 & 30 \\
160 & 80 & 40
\end{tabular}

Part 2: FR Constant, Key Force Increased Each Session

Condition No.

FR Requirement

$\underline{\text { Unit Price }}$

10

20

40

60

80

\begin{tabular}{lcc}
4 & 5 & 6 \\
20 & 10 & 5 \\
& Key Force (N) & \\
\hline 0.5 & 1 & 2 \\
1 & 2 & 4 \\
2 & 4 & \\
3 & & \\
4 & &
\end{tabular}

increased each session). There were six of these identical combinations, each occurring twice. Differences in the consumption-rate data from these six combinations were generally not large (the standard deviations of the absolute differences in the log consumption rates ranged from 0.036 to 0.205 , with one exception (0.636)), and the estimates were not reliably higher or lower depending on the variable being manipulated across sessions. This indicates that the consumption rates at any particular FR and force combination did not vary systematically with the experimental path to that combination. To simplify data presentation further, the arithmetic average of the two logarithmic (to the base 10) consumption rates obtained at each particular combination of FR and force requirement were used. Comparisons of the original data sets with those that contained the averaged data showed that the individual trends were preserved.

No hen responded sufficiently for consumption-rate data to be gathered for all force and ratio combinations. This seems to have been a function of the force requirement rather than the FR size. All hens completed all combinations involving force requirements of $1 \mathrm{~N}$ or less. All but Hen 94 responded at every unit price involving the $2 \mathrm{~N}$ requirement. Only one hen (91) responded when a unit price included a force requirement that was $3 \mathrm{~N}$ or larger.

To examine the effects of the force and FR manipulations separately, the averaged consumption-rate data are plotted against FR size in Figure 1 (wherein the data from each force requirement are indicated and joined), and against force requirement in Figure 2 (wherein the data from each FR requirement are indicated and joined). All axes are logarithmic (to the base 10). Figure 1 shows that, in all but one case (Hen 94), the general data path is one of systematically lower consumption rates with FR increases. Most data (again Hen 94 was the excep- tion) fall almost linearly and are close to unit elasticity. There appears to be no consistent effect of force on the overall level of demand, in that no data path is consistently above or below the others.

Since most birds stopped responding at or before the third or fourth force requirement, the data paths in Figure 2 are necessarily short. With this limitation it is hard to detect consistent patterns across force requirements at each FR. However, where there are at least three data points, no consistent pattern of rising or falling in consumption rate appears evident over the first few force requirements. There were 21 cases where only one force requirement was completed at a particular FR. Where two were completed (10 cases), six of the consumption rates showed decreases with increased force, and four showed increases. There were no clear patterns in the six cases with three points in the data path. One rose overall, two fell and three were U-shaped. The only fourpoint data path (Hen 91 at an FR of 20) showed a small decrease over the first three force requirements, and a sharp fall at the fourth. Hence, there were no clear effects of force over the range(s) at which the hens responded. The effects of FR size can be seen in that the data from different FR requirements tend to fall separately, with higher FR requirements resulting in lower consumption rates.

Figure 3 presents the logarithms of the averaged consumption-rate data plotted against the logarithms of the unit prices (Equation 2) for each hen. Although the consumption rates decreased as unit price increased, it is clear that they would not be well described by a single function. The deviations from a single underlying unit price function do, however, appear to be systematic. To illustrate this pattern of deviation, consider the data of Hen 93, where the pattern is most clear. At any particular unit price the consumption rates are highest when the combination involved the lowest FR requirement (and highest force requirement, pluses), and lower when a combination involved the highest FR requirement (and lowest force requirement, diamonds). That is, the FR size has had a consistent effect on consumption rate at all unit prices, and this effect is in the expected direction, whereas force requirement has not. In general, the higher force requirements (and hence smaller FR requirements) were associated with higher consumption rates.

\section{Discussion}

The data in this experiment are not consistent with the prediction that consumption rate will be equivalent at equivalent unit prices (calculated using Equation 2), independent of the particular FR and force combination making up each unit price. Unlike Sumpter et al.'s (1999) unit price analysis, these data provided a direct test of this prediction as consumption rates at unit prices made up of more than one combination of FR and force requirement were compared. Differences in consumption rates as large as twentyfold were found at the same unit price. These clearly large differences indicate that one must take extreme caution when comparing animals' de- 

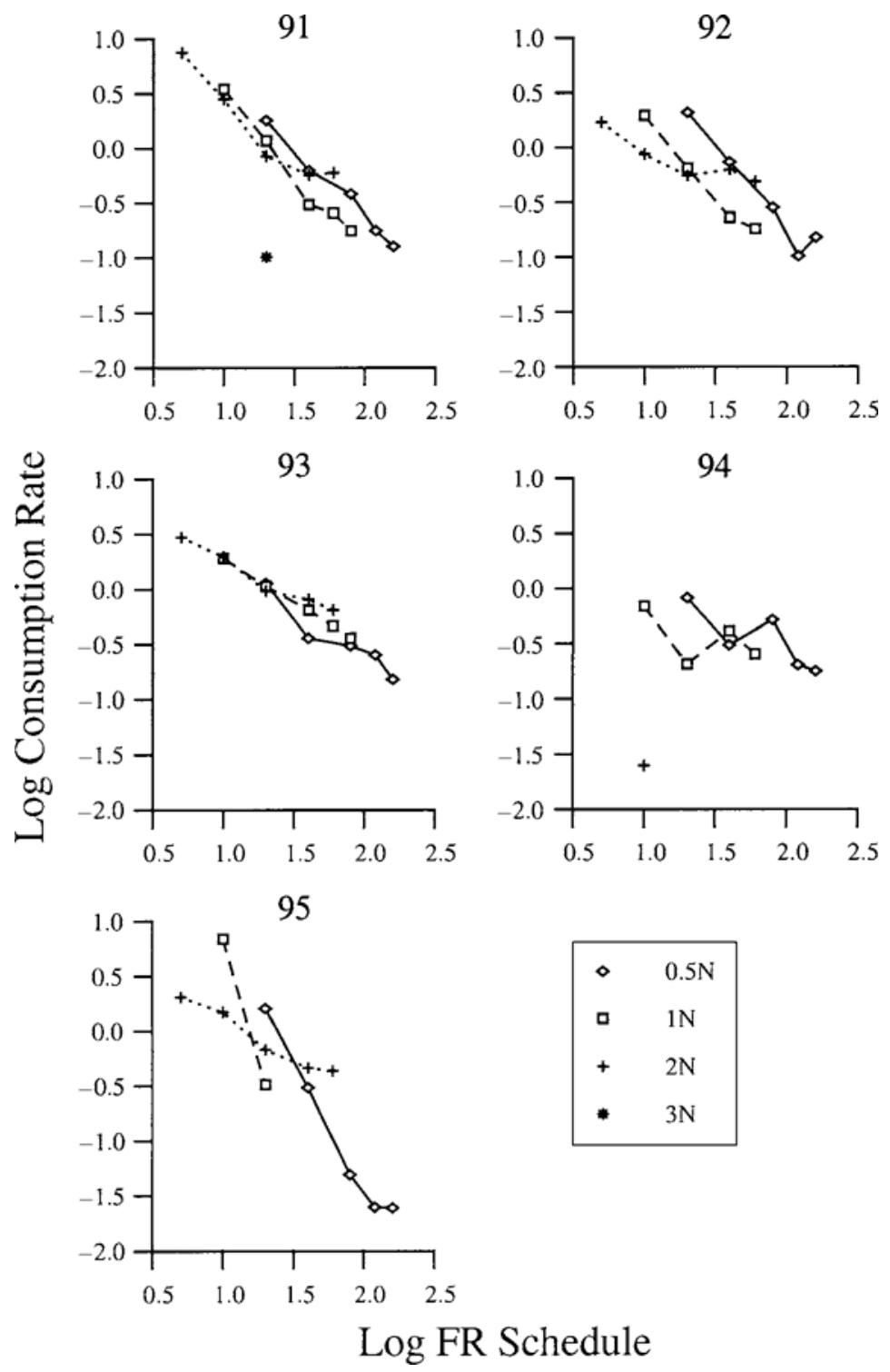

Figure 1. The logarithms of the averaged consumption-rate data from Experiment 1, plotted against the logarithms of the FR schedule size. The data obtained during exposure to each force requirement are indicated and joined.

mand for various commodities when different price manipulations are involved.

Underlying the proposed equation for unit price (Equation 2) is the assumption that both manipulations studied will have mathematically equivalent, graded effects on consumption rate (e.g., if doubling the FR size halves consumption rate, then doubling the force requirement would also have to halve consumption rate). The present data clearly suggest that changes in force requirement and FR size do not have equivalent effects on rate of consumption. Changes in FR requirement (at any particular force) gave approximately linear changes in consumption rate (Figure 1), whereas changes in force (at a particular FR) had apparently nonlinear and inconsistent ef- fects (Figure 2). Such results are consistent with the findings of Sumpter et al. (1999) who found, using a doorpush response, that although consumption rates decreased approximately linearly across FR increases, the changes were nonlinear across force requirements.

The question arises as to the physical capability of the individual hens to perform the required responses at high force levels. With keypeck forces of 0.5 and $1 \mathrm{~N}$, all hens completed sufficient FR requirements for any suggestion of physical limitation to be disregarded. With a force requirement of $2 \mathrm{~N}$, all but Hen 94 did likewise. At $3 \mathrm{~N}$, only Hen 91 completed any full FR requirement. It is clear, then, that there were, for each hen, forces beyond which that hen did not respond. 

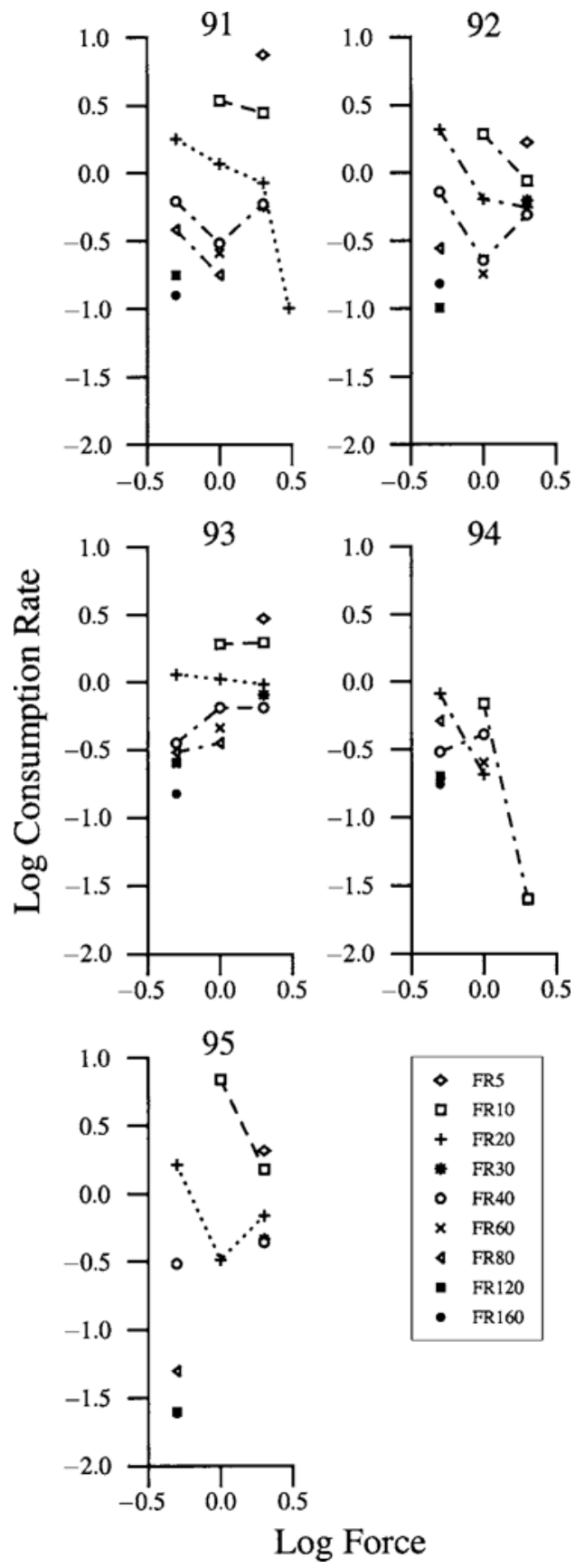

Figure 2. The logarithms of the averaged consumption-rate data from Experiment 1, plotted against the logarithms of the force requirements. The data obtained during exposure to each FR requirement are indicated and joined.

When the higher unit prices consisted of a low force requirement and a large FR requirement, the hens responded and collected reinforcers. When the same unit prices consisted of higher force requirements and smaller FR requirements, they did not. One explanation for this may lie in consideration of the nature of the keypeck response. It appears, particularly in hens, to be quite a dis- crete and "ballistic" response. Each hen's head seems to move a relatively constant distance with, possibly, a relatively constant force. If this description is accurate, changes in force requirement below a particular level may have little or no effect on responding (and hence consumption rate). Conversely, increases in force requirement beyond that level may cross a force threshold for each animal and lead to rapid declines in, or cessation of, responding (and hence reinforcement). This might account for the inconsistent effects of force on consumption rate (Figure 2) and the fact that all hens stopped responding and did not complete all unit price determinations involving a higher force requirement. At force requirements below threshold, it appears that the size of the FR requirement has a larger effect than any changes in force requirement. The larger the FR requirement, the lower the consumption rate. This may be expected on the basis of Sumpter et al.'s (1999) findings that larger FR requirements take more time, whereas increases in key force do not (at least over a moderate range).

The present findings, together with the suggestion that increases in key force below a particular threshold may have little effect on consumption rate, appear to be inconsistent with the findings of Alling and Poling (1995). They found that, for 2 out of 4 rats, there were graded decreases in response rate as the force required to make a leverpress was increased from 0.25 to $2 \mathrm{~N}$. This difference may be due to the topographically different responses employed. A leverpress seems to be a less discrete response than a keypeck and greater variations in applied force may be possible (Starin, 1989). In this respect, doorpushing in hens may be more similar to leverpressing in rats.

\section{EXPERIMENT 2}

The previous experiment did not allow exploration of the planned range of unit prices because the hens simply stopped pecking the key at high force requirements, thereby limiting the range of unit prices that could be studied. This next experiment was conducted to examine the usefulness of the unit price model in the analysis of consumption-rate data collected using a doorpush response. Hens have already been shown to doorpush over a wider range of force requirements than was found for the key in Experiment 1 (Sumpter et al., 1999). Sumpter et al.'s unit price analysis of their doorpush data was, however, post hoc. Like Experiment 1, the present experiment provided a direct test of the unit price model by arranging a series of unit prices (using Equation 2), each comprised of more than one force and FR combination. Using a doorpush response, examination of consumption rate across a wider range of unit prices should be possible.

\section{Method}

Subjects. Six Brown Shaver hens, numbered 91-96, served as subjects. These hens were raised in a large aviary and were approximately 1.5 years old when the experiment began. All but 1 hen (Hen 91) had previous experience on various schedules of rein- 

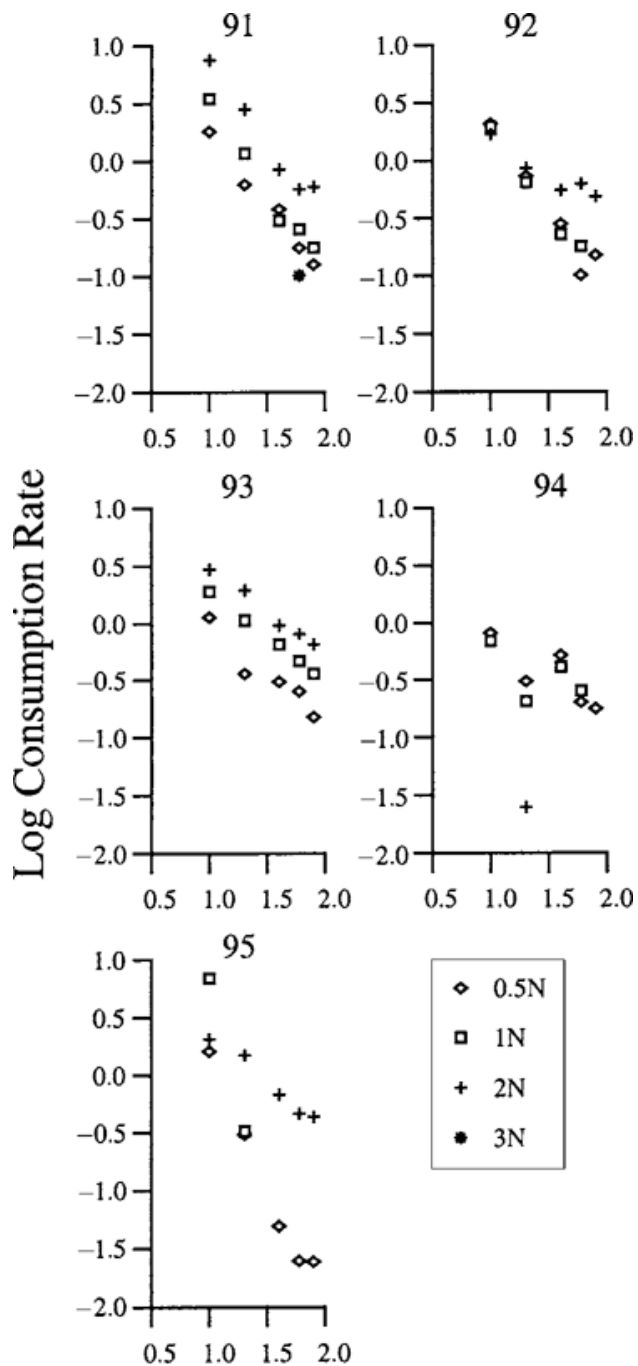

\section{Log Unit Price}

Figure 3. The logarithms of the averaged consumption-rate data from Experiment 1, plotted against the logarithms of the unit prices. The data obtained during exposure to each force requirement are indicated.

forcement. None of the hens had responded on a doorpush manipulandum. The housing and feeding conditions were the same as in Experiment 1.

Apparatus. The apparatus was identical in all but one respect to that used in Experiment 1. For this experiment, the response key was covered with a thin metal sheet and a door was attached to the front wall of the experimental chamber. The door was similar to that described in detail by Sumpter, Foster, and Temple (1995), and consisted of an "H-shaped" rectangular metal tube, situated $36 \mathrm{~cm}$ above the grid floor and $2 \mathrm{~cm}$ from the right wall, to which a microswitch was attached. The frame supported two bearing races. Carried in these bearings, and able to rotate, was a horizontal shaft of square steel tubing $17 \mathrm{~cm}$ long, $1.5 \mathrm{~cm}$ wide, and $1.5 \mathrm{~cm}$ deep, situated $33.5 \mathrm{~cm}$ from the grid floor. A metal arm, $15 \mathrm{~cm}$ long and $5 \mathrm{~cm}$ wide, was attached at right angles to the horizontal shaft, which, when an effective doorpush was made, contacted the mi- croswitch. A metal basket, $8 \mathrm{~cm}$ long, $8.5 \mathrm{~cm}$ wide, and 3.5 deep, was fastened onto the back end of the arm so that various sized weights could be placed on the door. Attached vertically on the horizontal shaft were two brass rods (through which the hens could push their heads and necks), which, when suspended, hung $4 \mathrm{~cm}$ inside the front wall and $10 \mathrm{~cm}$ above the grid floor. These rods needed to be pushed $5 \mathrm{~cm}$ forward (measured at the center of the rods) or to an angle of $15^{\circ}$ for an effective doorpush to be made. This movement operated a microswitch and required a minimum force of $2 \mathrm{~N}$ when no weights were placed in the basket.

A hole $(10 \times 19 \mathrm{~cm})$ was cut out of the front wall directly below the door frame and $11 \mathrm{~cm}$ from the floor. A box $27.5 \mathrm{~cm}$ long, $10 \mathrm{~cm}$ wide, and $18 \mathrm{~cm}$ deep was fixed to the rear of the front wall so that it now covered the hole. This meant that there was space for a hen's head when an effective doorpush was made. A 1-W white bulb located at the rear of this box provided illumination of the door.

During Conditions 1-22 of the experiment, the force required for a subject to push the door was increased by placing weights in the basket attached to the metal arm of the door. The required door forces were $2,4,8,16$, and $32 \mathrm{~N}$, measured with a calibrated spring balance (attached half-way down the right vertical rod).

After completion of Condition 22, the door was modified so that the minimum force required for a subject to make an effective doorpush was reduced. A minimum force of $1 \mathrm{~N}$ was achieved by replacing the $15-\mathrm{cm}-$ long metal arm with an aluminum arm that was only $5 \mathrm{~cm}$ long. A pulley system which acted to aid a doorpush was then added to achieve a minimum force of $0.5 \mathrm{~N}$. This arrangement decreased the angle (and the distance) that the door prongs had to be pushed from $15^{\circ}(5 \mathrm{~cm})$ to $10^{\circ}(3 \mathrm{~cm})$.

Procedure. The hens responded on a doorpush manipulandum, and their consumption rates at seven unit prices $(1,2,4,8,16,32$, and 64) were examined. As in Experiment 1, each of those unit prices was made up of different combinations of FR requirements and required door forces.

Throughout Conditions 1-5, the force required to push the door was held constant and the FR was changed each session. During Condition 1, no weights were placed on the door so the minimum force required to make an effective doorpush was $2 \mathrm{~N}$. In Conditions $2-5$, the minimum required door forces were $4,8,16$ and $32 \mathrm{~N}$, respectively. During Conditions 6-11, the unit prices were arrived at by holding the FR requirement constant and changing the required door force each session. The FR requirements used during Conditions 6-11 were FR 1, FR 2, FR 4, FR 8, FR 16, and FR 32, respectively.

Conditions 12-16 and Conditions 17-22 of this experiment were replications of Conditions $1-5$ and 6-11, respectively. Immediately prior to Condition 23, the door was modified so that the minimum force needed for a subject to push the door could be reduced to $0.5 \mathrm{~N}$ (Conditions 23 and 25) or $1 \mathrm{~N}$ (Conditions 24 and 26). The order of experimental conditions, together with the various FR and force requirements, and the corresponding unit prices are shown in Table 2.

All other aspects of the procedure were identical to those employed during Experiment 1, apart from the reinforcer access time. For this experiment, the reinforcer access time was increased to $3.5 \mathrm{sec}$ in order to give the hens enough time to move back from the door and still receive approximately 3 -sec access to wheat.

\section{Results}

Consistent with the results of Experiment 1, the differences in the log consumption-rate data from the replicated conditions of particular FR- or force-requirement changes were generally small. The standard deviations of the absolute differences ranged from 0.043 to 0.550 $\log _{10}$ units across the 174 possible comparisons, and ex- 
Table 2

Order of Experimental Conditions Together With FR Requirements and Required Door Forces in Effect

\begin{tabular}{|c|c|c|c|c|c|c|}
\hline \multicolumn{7}{|c|}{ Parts 1 and 3: Door Force Constant, FR Increased Each Session } \\
\hline $\begin{array}{l}\text { Condition No. } \\
\text { Door Force }(\mathrm{N})\end{array}$ & $\begin{array}{c}1 \& 12 \\
2\end{array}$ & $\begin{array}{c}2 \& 13 \\
4\end{array}$ & $\begin{array}{c}3 \& 14 \\
8\end{array}$ & $\begin{array}{c}4 \& 15 \\
16\end{array}$ & $\begin{array}{c}5 \& 16 \\
32\end{array}$ & \\
\hline Unit Price & \multicolumn{6}{|c|}{ FR Requirement } \\
\hline 2 & 1 & & & & & \\
\hline 4 & 2 & 1 & & & & \\
\hline 8 & 4 & 2 & 1 & & & \\
\hline 16 & 8 & 4 & 2 & 1 & & \\
\hline 32 & 16 & 8 & 4 & 2 & 1 & \\
\hline 64 & 32 & 16 & 8 & 4 & 2 & \\
\hline \multicolumn{7}{|c|}{ Parts 2 and 4: FR Constant, Door Force Increased Each Session } \\
\hline Condition & $6 \& 17$ & $7 \& 18$ & $8 \& 19$ & $9 \& 20$ & $10 \& 21$ & $11 \& 22$ \\
\hline FR & 1 & 2 & 4 & 8 & 16 & 32 \\
\hline Unit Price & \multicolumn{6}{|c|}{ Door Force $(\mathrm{N})$} \\
\hline 2 & 2 & & & & & \\
\hline 4 & 4 & 2 & & & & \\
\hline 8 & 8 & 4 & 2 & & & \\
\hline 16 & 16 & 8 & 4 & 2 & & \\
\hline 32 & 32 & 16 & 8 & 4 & 2 & \\
\hline 64 & - & 32 & 16 & 8 & 4 & 2 \\
\hline \multicolumn{7}{|c|}{ Part 5: Door Force Constant, FR Increased Each Session } \\
\hline Condition & $23 \& 25$ & $24 \& 26$ & & & & \\
\hline Door Force $(\mathrm{N})$ & 0.5 & 1 & & & & \\
\hline Unit Price & \multicolumn{2}{|c|}{ FR Size } & & & & \\
\hline 1 & 2 & 1 & & & & \\
\hline 2 & 4 & 2 & & & & \\
\hline 4 & 8 & 4 & & & & \\
\hline 8 & 16 & 8 & & & & \\
\hline 16 & 32 & 16 & & & & \\
\hline 32 & 64 & 32 & & & & \\
\hline 64 & 128 & 64 & & & & \\
\hline
\end{tabular}

ceeded 0.217 only when the force requirements were large (i.e., $8 \mathrm{~N}$ or greater). Moreover, the direction of the differences in the replicated consumption rates did not differ systematically across hens or conditions. Therefore, the data from only the last of these conditions are used in the analyses. Because the calculated differences between the two log consumption rates obtained from each of the 18 repeated combinations of FR and force requirement (e.g., FR 2 at $2 \mathrm{~N}$ during Conditions 12 and 18 ) were also generally small (standard deviations of the absolute differences ranging from 0.010 to $0.202 \log _{10}$ units) and did not differ systematically in direction, the arithmetic average of those log consumption rates were calculated for each hen and used in the analyses. In the rare cases in which a hen responded during only one instance of a combination (e.g., when the response requirement was arrived at by increasing force rather than FR size each session), which occurred only when a combination involved a very high force requirement, the data from the session in which the hen did respond were used. Again, this simplified the data presentation while still preserving the trends observed in the original data sets.

The logarithms of these averaged consumption rates are plotted against the logarithms of the FR schedule size in Figure 4, and against the logarithms of the force requirements in Figure 5. Again, all logarithms are to the base 10. In Figure 4, the data from the different force requirements are indicated and joined, whereas in Figure 5, the data are joined by FR size. Figure 4 shows that, irrespective of the force requirement, consumption rate decreased in an approximately linear fashion with increases in FR size. Again, increases in force requirement appear to have had no consistent or graded effect on the overall levels of consumption rate, in that the data from the combinations involving the $0.5,1,2$, and $4 \mathrm{~N}$ force requirements tend to fall on top of each other and in no particular order. Only when the force requirement is large (i.e., 8 and $16 \mathrm{~N}$ ) is there some evidence of lower consumption rates at the highest force requirements.

The nonlinear effects of force requirement on consumption rate can be seen more clearly in Figure 5. At FR requirements at or below FR 8, the low to moderate force requirements (i.e., $0.5,1,2$, and $4 \mathrm{~N}$ ) had very little effect on consumption rate. That is, the consumption rates remained relatively constant and inelastic across those low to moderate force requirements. Further increases in force, however, produced fairly abrupt drops in consumption rate. At the larger FR requirements em- 

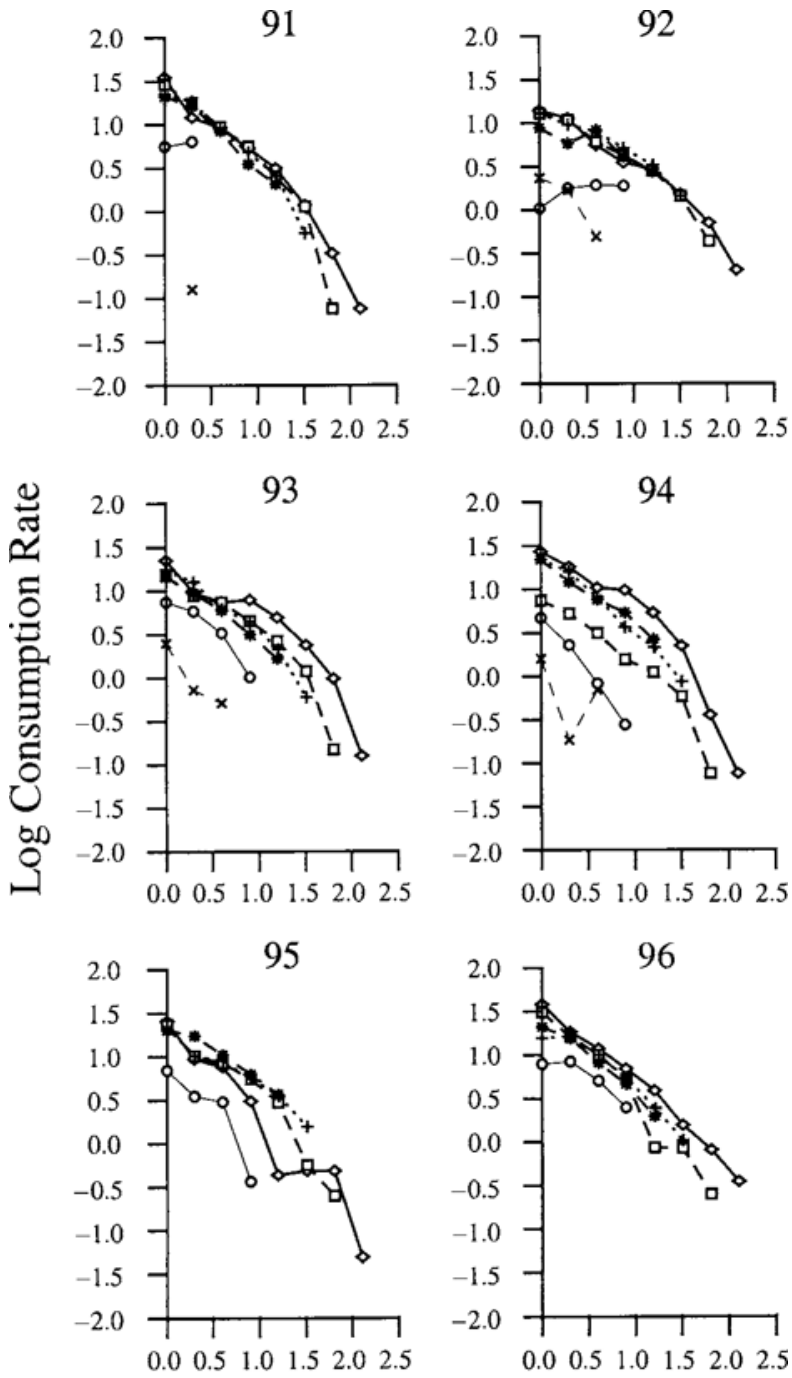

Log FR Schedule

$\begin{array}{ll}\bullet 0.5 \mathrm{~N} & \bullet 4 \mathrm{~N} \\ \square 1 \mathrm{~N} & \circ 8 \mathrm{~N} \\ +2 \mathrm{~N} & \times 16 \mathrm{~N}\end{array}$

Figure 4. The logarithms of the averaged consumption-rate data from Experiment 2, plotted against the logarithms of the FR schedule size. The data obtained during exposure to each force requirement are indicated and joined.

ployed, however, relatively small increases in force produced fairly rapid decreases in consumption rate. It can also be seen that the increases in FR requirement had not only large, but consistent, effects on the rate of consumption. This is evidenced by the data paths joining each FR size falling separately, with higher FR requirements resulting in systematically lower consumption rates.
Figure 6 shows the logarithms of the averaged consumption-rate data, analyzed as above, plotted against the logarithms of the unit prices (Equation 2) for each hen. The data presented in this figure are clearly more unified than those in Figure 5 (plotted against force) and are also more unified than those in Figure 4 (plotted against FR size). At any particular unit price, force requirements over the range of 0.5 to $4 \mathrm{~N}$ (up to $8 \mathrm{~N}$ for Hens 93 and 96) gave orderly patterns in which the highest forces (and lowest FR values) produced the highest consumption rates, with the other values falling below them usually in order of increasing FR size (and decreasing force requirement). Once the force requirements became higher than this, however, the data points were generally quite low and no longer follow the pattern described.

\section{Discussion}

The findings of Experiment 2 support and extend the findings of Experiment 1 and those of Sumpter et al. (1999). Increases in FR requirement change consumption rate in a relatively linear fashion, whereas changes in force requirement produce generally nonlinear (flat then sharply falling) changes in consumption rate. This finding is broadly, but probably not totally, independent of the topography of the response, at least across the two responses used here.

To understand the differences in the shapes of the functions, consider the effects of changes in requirement on the time taken to complete a response unit. As Sumpter et al. (1999) pointed out, when animals respond at close to their maximum rate throughout the session, increases in FR size will necessarily increase this time, thereby imposing a ceiling on the consumption rate dependent on the maximum response rate of the animal. Constant response rates, in the face of FR increases, will lead to linear demand functions with slopes of -1.0 , much as were found here. In contrast, increases in force requirement do not necessarily increase the time required for a subject to complete the response unit. From the present data, especially those from the doorpush, it seems that increases in force below a particular level for each hen did not affect the time taken to complete a response unit and the consumption rates did not drop with increasing force. Once the force requirement passed this level, responding (and consumption rate) dropped abruptly. This appears to be the case more for keypecking than for doorpushing and may reflect something about the topographical differences between the responses.

Keypecking stopped quite abruptly rather than slowed as force was increased (Figure 3). For the doorpush, although the drops in the consumption rates were somewhat abrupt at the higher force requirements, the hens did continue to doorpush at lower rates before stopping completely (Figure 5). In contrast to keypecking, which we argue is a ballistic response, doorpushing is a gross motor response involving most of the animal's body. Our own observations have revealed that the doorpush topog- 

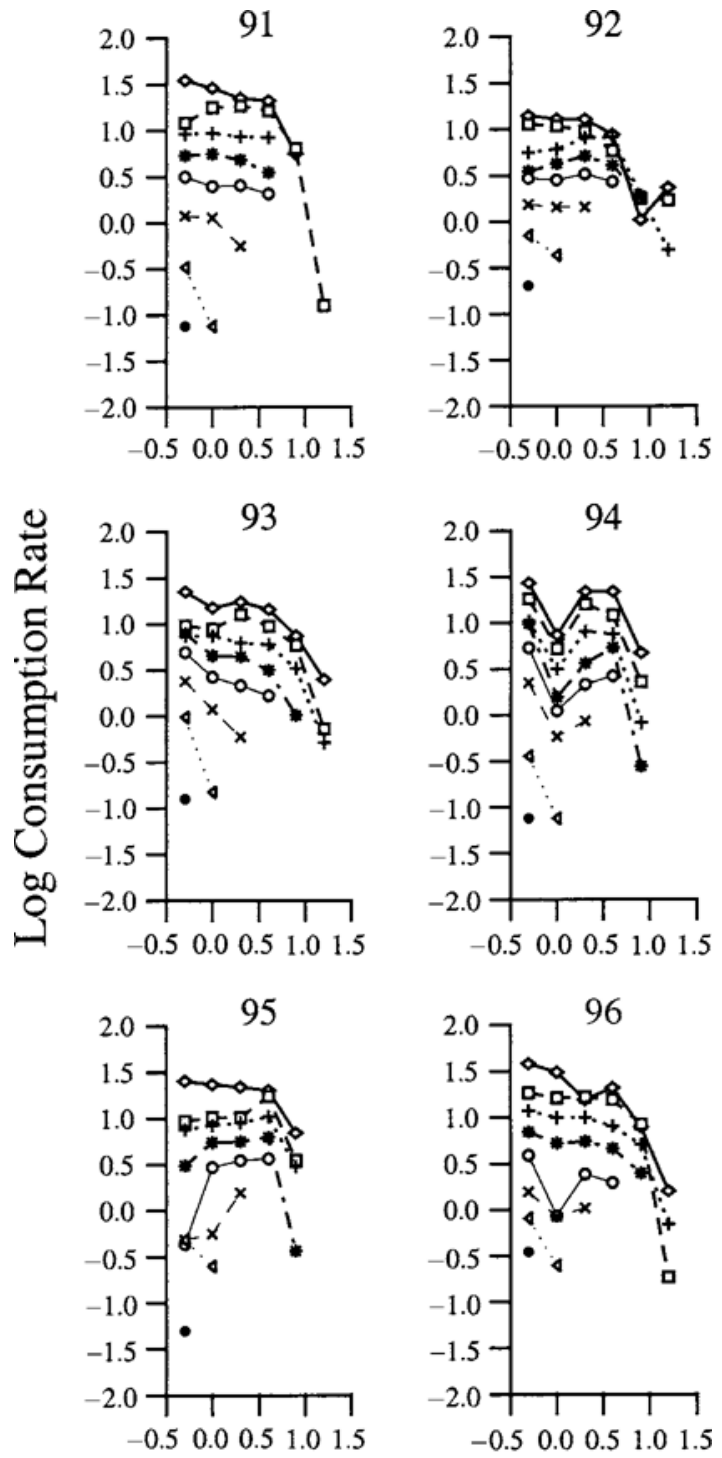

\section{Log Force}

\begin{tabular}{|llll|}
\hline$\bullet$ & FR1 & $\circ$ & FR16 \\
$\bullet$ & FR2 & $\times$ & FR32 \\
+ & FR4 & $\triangleleft$ & FR64 \\
$\bullet$ & FR8 & $\bullet$ & FR128 \\
\hline
\end{tabular}

Figure 5. The logarithms of the averaged consumption-rate data from Experiment 2, plotted against the logarithms of the force requirements. The data obtained during exposure to each FR requirement are indicated and joined.

raphy varies both between hens and within individual hens. Such topographical changes may allow changes in the force applied, but again our data suggests, since most data paths fell rather steeply (Figure 5), that at the upper end there is a clear limit to the force at which each hen would continue to respond. Again, the fact that the hens completed some FR requirements at all force requirements from which data are presented (Figure 5) indicates that these were within their physical capabilities and eliminating any would be arbitrary.

The forces at which the hens keypecked covered only a limited range. It seems fair to assume that if we had been able to vary the force required for a keypeck over a wider range, particularly one that included lower values, then we would have found functions similar to those for doorpushing with long, flattish, left-hand portions. Equipment limitations meant that we could not arrange any force lower than $0.5 \mathrm{~N}$, or use smaller step sizes. Smaller increments over the range of $1-4 \mathrm{~N}$ might also have provided some slower, but nonzero, consumption rates at the right-hand end of the functions. However, if keypecking does occur at an approximately constant, maximum, force, then changes below this will have little effect, whereas forces beyond this would result in zero consumption rates.

Differences in the way in which the two price manipulations alter consumption rate pose a problem for the unit price model proposed. When manipulations of response parameters do not produce equivalent effects on consumption rate, particularly when one is linear and the other is not, then unit price as defined by Equation 2 will not draw them onto a single function. Similarly, if reinforcer parameters have different effects on total consumption as was found by English, Rowlett, and Woolverton (1995), then unit price as defined by Equation 1 will not unify the data. This is because the unit price model involves simple multiplicative combinations of response and reinforcer parameters and assumes therefore that equivalent changes in each parameter produce equivalent changes in consumption. The fact that this is not the case in our data should not come as a surprise since nonlinear relations between physical and psychological (i.e., perceived) events are well known in psychophysics.

This article and that of Sumpter et al. (1999) argue that force and ratio requirement increases have different effects on consumption rate because of the time constraints that ratio, but not force, changes entail. However, implicit in the unit price analysis is an unstated assumption that equal unit prices should involve equal effort or energy expended. This may offer another explanation. If a keypeck is quite ballistic, the energy expended will be approximately constant regardless of the force requirement on the key, as long as that requirement is below a certain level. Hence, at any particular FR requirement, increases in force (below threshold) will not change the energy expended and will function as a constant price giving approximately constant consumption rates as was found in the keypeck, and to a lesser extent, doorpush data. The same argument does not apply as strongly to the doorpushing data but still might apply across the flatter portion of the functions found when consumption rate was plotted against force increases. If this energy-based explanation holds, data collected in sessions with no time constraints should show functions shaped similarly to those found here. It remains to be seen whether similar 

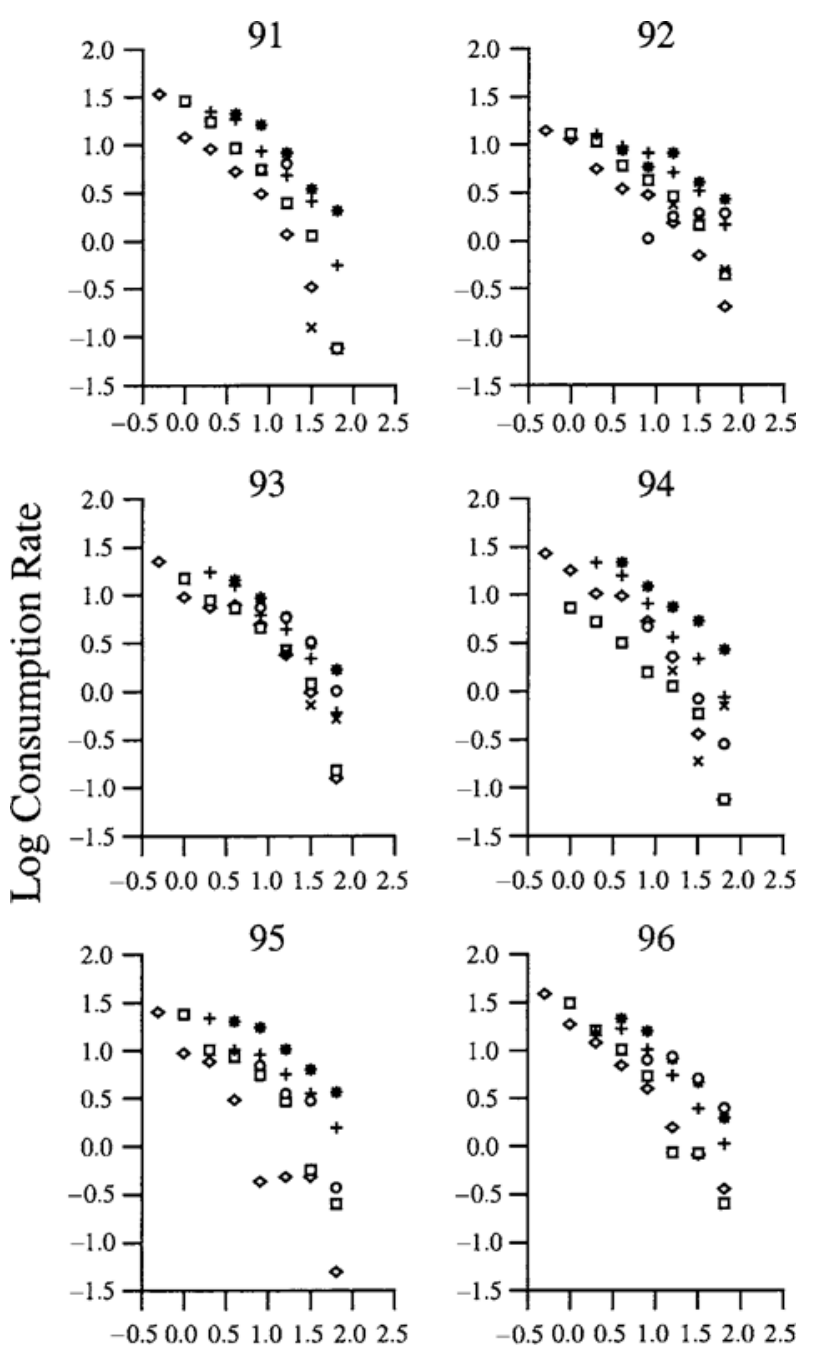

\section{Log Unit Price}

\begin{tabular}{|llll}
$\bullet$ & $0.5 \mathrm{~N}$ & $*$ & $4 \mathrm{~N}$ \\
- & $1 \mathrm{~N}$ & $\circ$ & $8 \mathrm{~N}$ \\
+ & $2 \mathrm{~N}$ & $\times$ & $16 \mathrm{~N}$
\end{tabular}

Figure 6. The logarithms of the averaged consumption-rate data from Experiment 2, plotted against logarithms of the unit prices. The data obtained during exposure to each force requirement are indicated.

conclusions hold when the unit price model is used to compare demand measures generated by different price manipulations under closed economic conditions.

It would be possible to adapt the unit price equation to fit the present data by transforming the scale measuring force requirement to render the function linear. However, employing such post hoc manipulations without a sound theoretical underpinning would essentially be a circular reasoning process. Certainly, they would not seem to form a reliable or valid basis for using demand functions as a means of assessing animals' needs.

\section{REFERENCES}

Alling, K., \& Poling, A. (1995). The effects of differing responseforce requirements on fixed-ratio responding of rats. Journal of the Experimental Analysis of Behavior, 63, 331-346.

DawKINS, M. S. (1983). Battery hens name their price: Consumer demand theory and the measurement of ethological "needs." Animal Behaviour, 31, 1195-1205.

Dawkins, M. S. (1990). From an animal's point of view: Motivation, fitness, and animal welfare. Behavioral \& Brain Sciences, 13, 1-61.

English, J. A., Rowlett, J. K., \& Woolverton, W. L. (1995). Unitprice analysis of opioid consumption by monkeys responding under a progressive-ratio schedule of drug injection. Journal of the Experimental Analysis of Behavior, 64, 361-371.

FoLTIN, R. W. (1991). An economic analysis of "demand" for food in baboons. Journal of the Experimental Analysis of Behavior, $\mathbf{5 6}, 445$ 454.

Foster, T. M., Blackman, K. A., \& Temple, W. (1997). Open versus closed economies: Performance of domestic hens under fixed-ratio schedules. Journal of the Experimental Analysis of Behavior, 67, 6789 .

Foster, T. M., Temple, W., Cameron, B., \& Poling, A. (1997). Demand curves for food in hens: Similarity under fixed-ratio and progressiveratio schedules. Behavioural Processes, 39, 177-185.

HURSH, S. R. (1980). Economic concepts for the analysis of behavior. Journal of the Experimental Analysis of Behavior, 34, 219-238.

Hursh, S. R. (1984). Behavioral economics. Journal of the Experimental Analysis of Behavior, 42, 435-452.

Hursh, S. R., Raslear, T. G., Shurtleff, D., Bauman, R., \& SimMONS, L. (1988). A cost-benefit analysis of demand for food. Journal of the Experimental Analysis of Behavior, 50, 419-440.

HURSH, S. R., \& WINGER, G. (1995). Normalized demand for drugs and other reinforcers. Journal of the Experimental Analysis of Behavior, 64, 373-384.

RASLEAR, T. G., Bauman, R. A., Hursh, S. R., ShurtlefF, D., \& SimMONS, L. (1988). Rapid demand curves for behavioral economics. Animal Learning \& Behavior, 16, 330-339.

STARIN, S. (1989). Choice and terminal-link response topography. Journal of the Experimental Analysis of Behavior, 51, 243-257.

Sumpter, C. E., Foster, T. M., \& Temple, W. (1995). Predicting and scaling hens' preferences for topographically different responses. Journal of the Experimental Analysis of Behavior, 63, 151-163.

Sumpter, C. E., Temple, W., \& Foster, T. M. (1999). The effects of different response types and price manipulations on demand measures. Journal of the Experimental Analysis of Behavior, 71, 329354.

Tsunematsu, S. (2001). Effort- and time-cost effects on demand curves for food by pigeons under short session closed economies. Behavioural Processes, $, \mathbf{5 3}, \underline{47-56}$.

(Manuscript received July 9, 2003; revision accepted for publication September 10, 2003.) 